Article

\title{
Socioeconomic Disparities in Hypertension by Levels of Green Space Availability: A Cross-Sectional Study in Philadelphia, PA
}

\author{
Celina Koh ${ }^{1,2}$, Michelle C. Kondo ${ }^{3}\left[\right.$, Heather Rollins ${ }^{2}\left(\mathbb{D}\right.$ and Usama Bilal ${ }^{1,2, *(\mathbb{C})}$ \\ 1 Department of Epidemiology and Biostatistics, Drexel University Dornsife School of Public Health, \\ 3215 Market St., Philadelphia, PA 19104, USA; ck876@dragons.drexel.edu \\ 2 Urban Health Collaborative, Drexel University Dornsife School of Public Health, 3600 Market St., \\ Philadelphia, PA 19104, USA; her43@drexel.edu \\ 3 Northern Research Station, United States Department of Agriculture-Forest Service, 100 N. St., Ste 205, \\ Philadelphia, PA 19103, USA; michelle.c.kondo@usda.gov \\ * Correspondence: ub45@drexel.edu; Tel.: +1-267-359-6378
}

Citation: Koh, C.; Kondo, M.C.; Rollins, H.; Bilal, U. Socioeconomic Disparities in Hypertension by Levels of Green Space Availability: A Cross-Sectional Study in Philadelphia, PA. Int. J. Environ. Res. Public Health 2022, 19, 2037. https://doi.org/ 10.3390/ijerph19042037

Academic Editor: Paloma Cariñanos

Received: 13 December 2021

Accepted: 8 February 2022

Published: 11 February 2022

Publisher's Note: MDPI stays neutral with regard to jurisdictional claims in published maps and institutional affiliations.

Copyright: (C) 2022 by the authors. Licensee MDPI, Basel, Switzerland. This article is an open access article distributed under the terms and conditions of the Creative Commons Attribution (CC BY) license (https:// creativecommons.org/licenses/by/ $4.0 /)$.

\begin{abstract}
Green spaces have been proposed as equigenic factors, potentially mitigating health disparities. We used data from the 3887 participants residing in Philadelphia who participated in the Public Health Management Corporation's Southeastern Pennsylvania Household Health Survey in 2014-2015 to assess whether socioeconomic disparities in hypertension are modified by availability of neighborhood-level green spaces. Socioeconomic status (SES) was measured using individuallevel education and neighborhood-level median household income. Green space availability was measured using surrounding percent tree canopy cover, mean normalized difference vegetation index (NDVI), and proximity to nearest park. Using logistic regression models adjusted for age, sex, and race/ethnicity, we found that adults with higher educational attainment had significantly lower levels of hypertension $(\mathrm{OR}=0.63,0.57$, and 0.36 for high school, some college, and college graduates, respectively, as compared to those with less than high school education), and this pattern was similar for median household income (higher prevalence in lower income areas). We found no significant interaction between education and percent tree canopy cover $(p=0.83)$, meaning that educational disparities in hypertension were similar across all levels of green space availability. These results held when using mean NDVI or distance to nearest park as availability measures, or when considering neighborhood-level median household income as the socioeconomic measure, although the specific patterns and significance of interactions varied by exposure and modifier. While socioeconomic disparities in hypertension are strong for adults residing in Philadelphia, green spaces did not seem to modify them.
\end{abstract}

Keywords: green spaces; hypertension; socioeconomic status; health equity; Philadelphia

\section{Introduction}

Green spaces can provide a wide variety of environmental, health, and equity benefits. Environmental benefits of green space, defined as land that is partially or completely covered in vegetation (e.g., grass, trees, shrubs, etc.) [1], include negating urban heat [2], minimizing air pollution [3], and regulating flooding [4]. Green spaces may also have health promoting benefits for outcomes such as mental health [4,5], physical activity and obesity [6-8], social cohesion [9], stress [10,11], restoration [12-14], pregnancy outcomes [15,16], and cardiovascular health [17-25]. Studies exploring the relationship between green spaces and health have used various measures for green space availability, including tree canopy cover, measures of green reflectance such as the Normalized Difference Vegetation Index (NDVI) or the Soil-adjusted Vegetation Index (SAVI), distance to various green spaces (e.g., parks), and presence of residential/neighborhood green spaces [26]. Since these measures represent different aspects of green space and its availability, and have exhibited 
differential associations with health outcomes, exploring multiple measures is key to better understand the linkages between green spaces and population health $[27,28]$.

Another benefit of green spaces is a phenomenon known as the equigenesis (or equigenic) hypothesis of green spaces [29]. According to this hypothesis, green spaces promote health equity by supporting the health of residents in less advantaged neighborhoods and thereby reducing socioeconomic status (SES)-based disparities in cardiovascular mortality and mental health outcomes $[4,5,30,31]$. This mitigation of disparities is especially important as ensuring health equity is a cross-cutting theme for public health [32]. However, the measurement of SES is complex, as it constitutes a multidimensional construct, usually measured with indicators of income or wealth, education, and occupation [33].

There are wide socioeconomic disparities in cardiovascular disease (CVD) and its risk factors. For example, both the incidence and prevalence of CVD and its risk factors tend to be higher in people with lower income, lower educational attainment, and in working class individuals [34-39]. Specifically, people living in poverty, with less than a high school education, and who work in manual occupations tend to have a higher prevalence of hypertension [40]. Nevertheless, hypertension remains the leading risk factor driving preventable deaths globally [41]. In this study, we focus on hypertension disparities by educational attainment (the highest level of education an individual has completed) [42] and median household income [43] to further understand factors that may narrow these disparities. Investigating the potential relationship between SES-based disparities and hypertension prevalence could improve health outcomes by providing opportunities to reduce inequalities through evidence-based interventions.

A few studies have examined the influence of green spaces on the relationship between socioeconomic factors and CVD and its antecedents, including hypertension [25,29,30,44-47]. Overall, these studies found mixed results, with some of them showing clear equigenic effects of green spaces [29], some finding a widening of inequalities in greener areas [46,47], and some finding inconclusive results $[25,30,44]$.

In order to further explore the equigenic effect of green spaces (narrower disparities in greener areas), and in view of conflicting results in previous research, we analyzed the relationship between green space availability and socioeconomic disparities in hypertension prevalence in Philadelphia from the period of 2014-2015. We leveraged data on multiple SES and green space indicators in an urban area with wide socioeconomic disparities, but with a committed effort to greening [48] and its equity consequences $[49,50]$. Based on previous studies and the potential effect of wide socioeconomic disparities across accessibility of green spaces and hypertension prevalence, we aimed to address two main hypotheses: (1) adults who have lower educational attainment will have greater odds of hypertension compared to those who have higher educational attainment and (2) adults who have higher green space availability will have narrower income-based and educational disparities in hypertension compared to those with lower green space availability (equigenic hypothesis).

\section{Materials and Methods}

\subsection{Study Setting}

We conducted a multilevel study of individuals nested in census tracts. The United States Census Bureau defines census tracts as statistical subdivisions of a county or equivalent [51]. We selected census tracts as the geographical unit of analysis due to accessibility of geocoding to complete, available, individual-level data. We obtained individual-level self-reported data on hypertension, age, sex, race/ethnicity, and education status from the Public Health Management Corporation's Southeastern Pennsylvania Household Health Survey (SEPAHHS) 2014-2015 wave dataset. SEPAHHS includes information collected from adults ( $\geq 18$ years old) living in Philadelphia, Bucks, Chester, Delaware, and Montgomery Counties via random digit dialing (landline and cell phone) administered in both English and Spanish [52]. The survey is conducted every 2 to 3 years and collects selfreported health status, health behaviors, and access to care [52]. The survey is designed to be representative of the adult non-institutionalized population of the area (see Table A4 
for a comparison of the sample with the population of Philadelphia). Our study sample has a similar hypertension, gender, and race/ethnic distribution to the population of Philadelphia, with a higher proportion of individuals aged 50-64.

The final analytic sample included 3887 adults (18+ years old) that had valid responses on all relevant variables residing in 377 census tracts in Philadelphia County (Figure 1). Philadelphia is the poorest large US city and has wide health disparities [53-56]. Furthermore, we decided to restrict the sample to Philadelphia to narrow the focus to an urban area, as green space availability (and its management) differs between the surrounding suburban and exurban counties. Moreover, Philadelphia has had several greening efforts over the last few decades [48] and has considered how equity affects greening strategies [49] in the management of urban parks and green space [50], making this a policy-relevant study location.

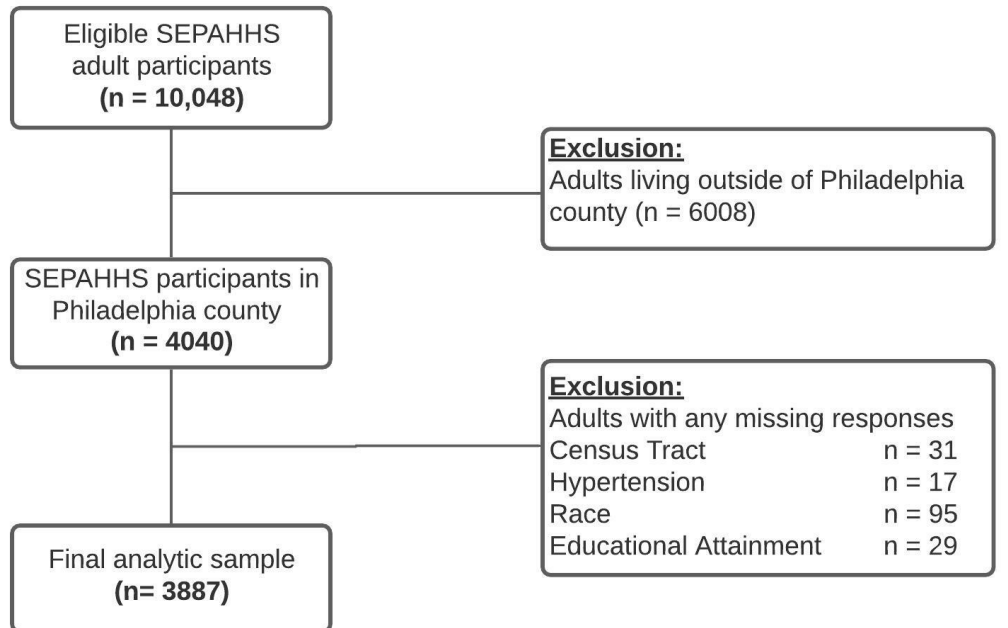

Figure 1. Exclusion criteria of the final analytic sample.

\subsection{Outcome (Hypertension)}

We defined hypertension status as self-reported high blood pressure, measured via responses to the survey question "Have you ever been told by a doctor or other health professional that you have high blood pressure or hypertension?" The available response categories were for yes, no, and only during pregnancy. We recategorized hypertension as a binary variable, operationalizing any observations that had reported hypertension only during pregnancy as no hypertension.

\subsection{Exposure}

We used two measures of SES: individual-level educational attainment and census tract-level median household income. Educational attainment was self-reported and obtained via survey response. Responses were categorized into four categories: less than high school, high school graduate (including high school graduates and General educational Development Test (GED)), some college or equivalent (including some college and technical, trade, and vocational school), and college graduate or higher. We selected these categories to be consistent with previous studies [30,34] and to avoid unbalanced categories with very low sample sizes. Median household income is another standard measure of SES. Individual-level income data were incomplete-missing for 869 out of the 3887 participants - which could cause potential issues if income was not missing at random. We therefore obtained census tract median household income from the 2012-2016 American Community Survey [57]. We were unable to account for 21 responses out of the 3887 participants due to missing median household income data per census tract (Figure A1). To make our analyses of this variable comparable with education (four categories), we operationalized median household income into quartiles (Table A1). 


\subsection{Effect Modifier (Green Spaces)}

We used three measures of green space availability at the census tract level, based on previous research $[20,23,30,34]$ : (1) percent tree canopy cover, (2) mean normalized difference vegetation index (NDVI), and (3) proximity to parks. First, we calculated tree canopy cover using raster-based tree canopy data derived from satellite imagery. The Chesapeake Bay Conservancy published high-resolution $\left(1 \mathrm{~m}^{2}\right)$ land cover data, including a tree canopy class, for the years 2014-2015 [58]. We computed percent tree canopy cover by dividing the tree cover area by the total area of each census tract. Second, we computed census tract-level mean NDVI using $250 \mathrm{~m}$ resolution data from the United States Geological Survey (USGS) for 2014-2015 utilizing the scale of -1 to 1 [59]. We recoded all values equal to -1 to No Data to remove water from our mean value calculations. Third, we calculated proximity to parks by computing the Euclidean distance from the centroid of each census tract of residence to the nearest park, where parks included community parks, farms, gardens, greenhouses, nurseries, linear parks, parkways, metropolitan parks, mini parks, neighborhood parks, regional/watershed parks, square/plaza parks, and watershed/conservation parks. We obtained location information for parks from the City of Philadelphia's Park and Recreation Department Parks Assets dataset from 2019 [60]. The dataset includes city-owned buildings and facilities (i.e., community parks, mini parks, watershed/conservation park, etc.) [60]. Table A2 contains more details on our inclusion criteria. We conducted all spatial analyses and calculations using ArcGISPro version 2.9.1 [61]. We operationalized all green space indicators by categorizing continuous variables into tertiles (Table A1).

\subsection{Covariates}

We included age, sex, and race/ethnicity a priori as confounders based on a literature review and a directed acyclic graph. We included race/ethnicity as a proxy for racism, a key factor that affects hypertension, socioeconomic opportunities, and neighborhood accessibility to green spaces through residential segregation $[62,63]$. Race/ethnicity was categorized into 4 groups: non-Hispanic white (NHW), non-Hispanic Black (NHB), Hispanic/Latino $(\mathrm{H})$, and Other. The "other" category, while collapsing widely distinct groups with different exposures, was needed since sample sizes for Asian $(\mathrm{N}=62)$, Biracial/Multiracial $(\mathrm{N}=139)$, and Native American $(\mathrm{N}=24)$ were low. Age and sex were included as they are important risk factors for hypertension. Age was categorized into four groups (18-34, 35-49, 50-64, $65+$ ). Similarly, sex was coded as a binary variable (male, female).

\subsection{Statistical Data Analysis}

The main objectives of this study were (1) to assess socioeconomic disparities in hypertension prevalence, and (2) to explore whether green space availability modifies socioeconomic disparities in hypertension prevalence. We set up a multilevel dataset, where each observation was an individual sampled in the SEPAHHS dataset, nested in a census tract. The dataset included individual-level variables (hypertension, age, sex, race, and education) and contextual-level variables (percent tree canopy cover, mean NDVI, proximity to nearest park, and median household income).

We fitted logistic regression models with hypertension (yes/no) as the outcome, adjusted for age, sex, and race/ethnicity, accounting for the survey clustering by census tract. In model 1, we included education as the key exposure. We hypothesized that individuals with lower educational attainment would have higher odds of hypertension. In model 2, we further adjusted for tertiles of tree canopy cover, and added an interaction between education and tree canopy cover. We hypothesized that educational disparities in hypertension would be narrower in areas with higher tree canopy cover. We tested the joint significance of interaction terms using the $\mathrm{F}$ test (categorical interaction in Figure A2). Furthermore, we also tested the significance of interactions using education or income as ordinal variables (ordinal interaction in Figure A2). We ran the following three secondary analyses: (1) changing the green space measure to mean NDVI, (2) changing the green 
space measure to distance to nearest park, and (3) changing the socioeconomic indicator to median household income.

To address the lack of independence between individuals living in the same census tract, all analyses used robust clustered standard errors at the census tract level. We also weighted all models to account for the balanced sampling weights of the SEPAHHS survey. All statistical analyses were conducted using $R$ version 4.0.1 [64].

\section{Results}

The descriptive characteristics of the final analytic sample of 3887 adults (18+ years old) residing in Philadelphia from the years 2014-2015 are displayed in Table 1. Overall, the proportion of individuals with hypertension in the final analytic sample was $43.2 \%$ $(\mathrm{N}=1679)$. Higher educational attainment was associated with an increased prevalence of hypertension, while it did not vary by levels of tree canopy cover, mean NDVI, and distance to nearest park. However, we observed large differences across age, race/ethnicity, and education in the prevalence of hypertension. Hypertension prevalence was highest among participants who were older, non-white, and had a lower educational attainment.

Table 1. Descriptive characteristics of included study participants.

\begin{tabular}{|c|c|c|c|}
\hline & \multicolumn{2}{|c|}{ Hypertension } & \multirow[b]{2}{*}{$\begin{array}{c}\text { Overall } \\
(\mathrm{N}=3887)\end{array}$} \\
\hline & $\begin{array}{c}\text { No } \\
(\mathrm{N}=\mathbf{2 2 0 8 )}\end{array}$ & $\begin{array}{c}\text { Yes } \\
(\mathrm{N}=1679)\end{array}$ & \\
\hline \multicolumn{4}{|l|}{ Tree Canopy Cover } \\
\hline Low & $682(57 \%)$ & $514(43 \%)$ & 1196 \\
\hline Medium & $701(53 \%)$ & $617(47 \%)$ & 1318 \\
\hline High & $825(60 \%)$ & $548(40 \%)$ & 1373 \\
\hline \multicolumn{4}{|l|}{ Mean NDVI } \\
\hline Low & $686(61 \%)$ & $439(39 \%)$ & 1125 \\
\hline Medium & $668(50 \%)$ & $679(50 \%)$ & 1347 \\
\hline High & $854(60 \%)$ & $561(40 \%)$ & 1415 \\
\hline \multicolumn{4}{|l|}{ Distance to Nearest Park } \\
\hline Low & $700(57 \%)$ & $532(43 \%)$ & 1232 \\
\hline Medium & $774(57 \%)$ & $578(43 \%)$ & 1352 \\
\hline High & $734(56 \%)$ & $569(44 \%)$ & 1303 \\
\hline \multicolumn{4}{|l|}{ Age (years) } \\
\hline $18-34$ & $462(87 \%)$ & $67(13 \%)$ & 529 \\
\hline $35-49$ & $771(75 \%)$ & $263(25 \%)$ & 1034 \\
\hline $50-64$ & $667(48 \%)$ & $716(52 \%)$ & 1383 \\
\hline $65+$ & $308(33 \%)$ & $633(67 \%)$ & 941 \\
\hline \multicolumn{4}{|l|}{ Sex } \\
\hline Male & $797(58 \%)$ & $586(42 \%)$ & 1383 \\
\hline Female & $1411(56 \%)$ & $1093(44 \%)$ & 2504 \\
\hline \multicolumn{4}{|l|}{ Race/Ethnicity } \\
\hline NH White $^{1}$ & $1087(65 \%)$ & $598(35 \%)$ & 1685 \\
\hline $\mathrm{NH}_{\text {Black }}{ }^{1}$ & $757(46 \%)$ & $874(54 \%)$ & 1631 \\
\hline Hispanic/Latino & $213(61 \%)$ & $135(39 \%)$ & 348 \\
\hline Other & $151(68 \%)$ & $72(32 \%)$ & 223 \\
\hline \multicolumn{4}{|l|}{ Educational Attainment } \\
\hline Less than high school & $142(37 \%)$ & $240(63 \%)$ & 382 \\
\hline High school graduate & $670(51 \%)$ & $654(49 \%)$ & 1324 \\
\hline Some college or equivalent & $531(57 \%)$ & $406(43 \%)$ & 937 \\
\hline College graduate or higher & $865(70 \%)$ & $379(30 \%)$ & 1244 \\
\hline \multicolumn{4}{|l|}{ Median Household Income } \\
\hline Q1 & $361(46 \%)$ & $416(54 \%)$ & 777 \\
\hline Q2 & $599(54 \%)$ & $517(46 \%)$ & 1116 \\
\hline Q3 & $627(59 \%)$ & $440(41 \%)$ & 1067 \\
\hline Q4 & $609(67 \%)$ & $297(33 \%)$ & 906 \\
\hline Missing & $12(57 \%)$ & $9(43 \%)$ & 21 \\
\hline
\end{tabular}

Note: All percent values displayed are row precents. This table shows raw counts and proportions (unweighted)

${ }^{1} \mathrm{NH}$ indicates non-Hispanic. 
Table 2 shows the results of model 1. We found a dose-response association between education and the odds of hypertension. Specifically, we found that, compared to individuals with less than high school education, after adjusting for age, sex, and race/ethnicity, individuals with high school education, some college, and college education had a 37\% (95\% CI: $10-56 \%$ ), 43\% (95\% CI: 15-62\%), and 64\% (95\% CI: 47-76\%) lower odds of hypertension. Table A3 shows results for median household income, showing analogous findings.

Table 2. Association between hypertension and education adjusted for age, sex, and race/ethnicity (Model 1).

\begin{tabular}{|c|c|c|}
\hline & OR $(95 \% \mathrm{CI})$ & $p$-Value \\
\hline \multicolumn{3}{|l|}{ Educational Attainment } \\
\hline Less than high school & 1.00 (Ref.) & \\
\hline High school graduate & $0.63(0.44 ; 0.90)$ & $0.012 *$ \\
\hline Some college or equivalent & $0.57(0.38 ; 0.85)$ & $0.005^{*}$ \\
\hline College graduate or higher & $0.36(0.24 ; 0.53)$ & $<0.001 *$ \\
\hline \multicolumn{3}{|l|}{ Age (years) } \\
\hline $18-34$ & 1.00 (Ref.) & \\
\hline $35-49$ & $3.07(2.02 ; 4.66)$ & $<0.001 *$ \\
\hline $50-64$ & $10.92(7.57 ; 15.75)$ & $<0.001 *$ \\
\hline $65+$ & $20.38(13.82 ; 30.04)$ & $<0.001 *$ \\
\hline \multicolumn{3}{|l|}{ Sex } \\
\hline Male & 1.00 (Ref.) & \\
\hline Female & $0.96(0.78 ; 1.19)$ & 0.73 \\
\hline \multicolumn{3}{|l|}{ Race/Ethnicity } \\
\hline NH White ${ }^{1}$ & 1.00 (Ref.) & \\
\hline NH Black ${ }^{1}$ & $2.28(1.79 ; 2.89)$ & $<0.001 *$ \\
\hline Hispanic/Latino & $1.17(0.77 ; 1.76)$ & 0.465 \\
\hline Other & $0.85(0.53 ; 1.37)$ & 0.513 \\
\hline
\end{tabular}

Note: Coefficients are shown as odds ratio (OR), and 95\% confidence interval (CI) from a weighted logistic regression model using generalized estimating equation (GEE). ${ }^{1} \mathrm{NH}$ indicates non-Hispanic. ${ }^{*} p<0.05$.

Figure 2 shows the results of model 2, estimating the association between hypertension and education by levels of tree canopy cover, adjusted for age, sex, and race/ethnicity. We found that education disparities in hypertension are similar across all levels of tree canopy cover ( $p$-value for the joint test of all interaction coefficients $=0.772 ; p$-value for the joint test of all interactions using ordinal education $=0.529$ ).

Lastly, we conducted two sets of sensitivity analyses (see Figure A2). First, we examined whether the patterns for education held for area-level median household income, an alternative SES indicator. While we found no significant interaction ( $p$-value for the joint test of all interaction coefficients $=0.192 ; p$-value for the joint test of all interactions using ordinal education $=0.459$ ), we found no income-based disparities in areas with high tree canopy cover. Second, we examined the robustness of the analysis by exchanging the green space availability measurement from percent tree canopy cover to mean NDVI or distance to nearest park. For mean NDVI, results were also qualitatively similar to the main analysis ( $p$-value for the joint test of all interaction coefficients $=0.961 ; p$-value for the joint test of all interactions using ordinal education $=0.864$ ). For distance to nearest park, we found a similar pattern to our main analysis, but with a significant interaction ( $p$-value for the joint test of all interaction coefficients $=0.017 ; p$-value for the joint test of all interactions using ordinal education $=0.068$ ), driven by a much lower prevalence of hypertension in people with college education in medium green space availability areas. 


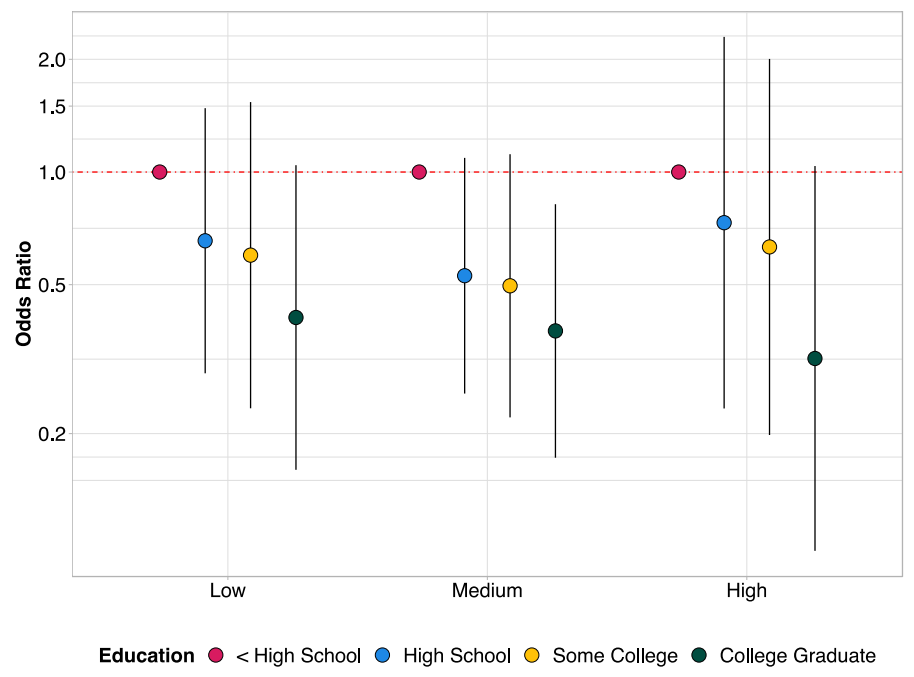

Figure 2. Comparisons of education disparities in hypertension across tertiles of tree canopy cover (Model 2). Note: Odds ratios are represented as the interaction terms between tree canopy cover and education. The reference group is less than high school education.

\section{Discussion}

In this analysis of 3887 adults residing in Philadelphia, we found a very wide socioeconomic disparity in hypertension after adjusting for age, sex, and race/ethnicity. However, we did not find support for the equigenic hypothesis, as we found that the educational disparity in hypertension was similar across all levels of green space availability. While these results were robust to the choice of green space measure or socioeconomic indicator, we did observe some differences in results across these alternative specifications.

Our finding of socioeconomic disparities of hypertension aligns with findings from previous studies of a strong association between hypertension and measures of socioeconomic status (SES), including education and income $[2-4,46,47]$. However, we did not find support for the equigenic hypothesis of green spaces for our outcome of self-reported hypertension. Specifically, we found similar educational disparities in hypertension across all levels of tree canopy cover and proximity to parks. Our findings were concurrent with one study that found no effect modification for education for both systolic and diastolic blood pressure [25].

On the other hand, four previous studies have found support for the equigenic hypothesis $[29,44,46,47]$. These studies used other SES indicators including household income, individual income, occupational class, neighborhood deprivation, and neighborhood median household income, for which we found more support for the equigenic hypothesis. These studies also used a diversity of green space availability measures, including green space coverage, mean NDVI, and the number of local areas used for parks and/or recreational facilities. While our findings were qualitatively similar across measures of green spaces, we did find more support for the equigenic hypothesis when examining distance to nearest park as the green space measure. Two studies suggested that reduction in hypertension risk among lower SES populations is related to higher levels of green space, specifically mean NDVI [46,47]. Meanwhile, the other two studies indicate similar iterations of the equigenic hypothesis in other health outcomes such as all-cause mortality [29] and cardiovascular-related diseases [44]. Overall, our results may not necessarily support or refute the hypothesis, but they do provide an additional opportunity to explore this relationship further.

The main strength of this study is the multilevel nature of the design, with individuallevel hypertension and education and neighborhood-level median household income, along with other confounders, and neighborhood-level measures of green space availability. Furthermore, we were able to test the robustness of our results using a different socioeconomic indicator (median household income) and measures of green space availability (mean 
NDVI and distance to nearest park). Lastly, all three models controlled for socioeconomic and demographic features while accounting for clustering within neighborhoods.

We also acknowledge several limitations. First, this is a cross-sectional study, and we were therefore unable to assess the temporality of associations or draw any causal inference. Second, hypertension was self-reported, which may introduce bias due to differential access to healthcare [65]. Third, we excluded 153 individuals because of missing data (4.2\% of the eligible sample) and were precluded from using individual-level reported income as a marker of SES given higher levels of missingness. However, we were able to leverage neighborhood-level median household income to conduct a secondary analysis. Fourth, the generalizability of this study is limited to adults living in large urban areas, given our restriction of the study sample to adults residing in Philadelphia. Fifth, green space availability was measured at the census tract level rather than at the residential address level, which could lead to misclassification of availability, and thereby lead to biases in our estimates. Additionally, the green space data from the Chesapeake Bay Conservancy and the City of Philadelphia's Parks and Recreation may be outdated in Philadelphia as urban green space design has been evolving towards renovated vacant lots and green roofs, which may not be included in either dataset [66]. Furthermore, the parks dataset does not include private green areas such as domestic gardens and backyards. We anticipate that the lack of inclusion of private green spaces introduces a possible issue of under-estimation of the effect of green space among affluent neighborhoods/participants. However, our analysis using cumulative green space (measured through mean NDVI) as the green space indicator showed similar results. Finally, we acknowledge that precent tree canopy, mean NDVI, and distance to nearest park do not fully represent green space availability as physical interaction/usage, accessibility, and urban integration should be considered as well.

\section{Conclusions}

The present study contributes to the current body of evidence by providing additional insight on the association between the proximity to green space and educational disparities in hypertension prevalence. Green space is a relatively novel tool for addressing health equity and outcomes for population health, and future studies can continue to improve on the measurement of both green spaces, markers of health disparities, and other health outcomes of interest.

Author Contributions: Conceptualization, C.K., M.C.K. and U.B.; Methodology, C.K., M.C.K. and H.R.; Software, C.K., H.R. and U.B.; Validation, H.R.; Formal Analysis, C.K. and H.R.; Investigation, C.K.; Resources, C.K., M.C.K. and U.B.; Data Curation, C.K. and H.R.; Writing-Original Draft Preparation, C.K.; Writing-Review and Editing, C.K., M.C.K., H.R. and U.B.; Visualization, C.K. and H.R.; Supervision, U.B.; Project Administration, U.B.; Funding Acquisition, U.B. All authors have read and agreed to the published version of the manuscript.

Funding: C.K. was partially supported by the Drexel Urban Health Collaborative applied practical experience award program. UB was supported by the Office of the Director of the National Institutes of Health under award number DP5OD26429. The funding agencies were not involved in the study design; in the data collection, analyses, or interpretation of data; in the writing of this work; or in the decision to submit the manuscript for publication.

Institutional Review Board Statement: The ethical review and approval were waived for this study by the integrative learning experience review committee of Drexel University, Philadelphia, CA, United States due to the research protocols not involving human subjects as defined by DHHS and FDA regulations.

Informed Consent Statement: Not applicable.

Data Availability Statement: Data provided by The Public Health Management Corporation's Community Health Database. In any event, this publication does not imply any representation that Public Health Management Corporation endorses or supports any position or views of Drexel University Dornsife School of Public Health. The Pennsylvania Land Cover of the Chesapeake Bay Conservancy and the Parks \& Recreation Assets datasets are publicly available. 
Acknowledgments: We thank the Urban Health Collaborative and Public Health Management Corporation for providing the data used in this study.

Conflicts of Interest: The funders had no role in the design of the study; in the collection, analyses, or interpretation of data; in the writing of the manuscript, or in the decision to publish the results.

\section{Appendix A}

Table A1. Categorization of median household income and green space accessibility measures.

\begin{tabular}{ll}
\hline \multicolumn{1}{c}{ Measure } & \multicolumn{1}{c}{ Categorization } \\
\hline & Q1 (USD 11,473 to 27,188) \\
Median household income & Q2 (USD 27,202 to 39,225) \\
& Q3 (USD 39,318 to 53,708) \\
& Q4 (USD 53,742 to 145,104) \\
Tree canopy cover & Low $(2-11.8 \%)$ \\
& Medium $(11.8-20.9 \%)$ \\
& High $(21.4-87.9 \%)$ \\
\hline & Low $(0-175.6 \mathrm{~m})$ \\
& Medium $(176.8-332.4 \mathrm{~m})$ \\
& High $(332.4-2222 \mathrm{~m})$ \\
\hline & Low $(-0.075$ to 0.142$)$ \\
Normalized Difference Vegetation Index (NDVI) & Medium $(0.142$ to 0.237$)$ \\
& High $(0.238$ to 0.530$)$ \\
\hline${ }^{1}$ Distance to nearest park was scaled by $400 \mathrm{~m}$ in the regression analysis.
\end{tabular}

Table A2. Inclusion criteria of green space features from Philadelphia Parks and Recreation Data.

\begin{tabular}{ll}
\hline \multicolumn{1}{c}{ Inclusion } & \multicolumn{1}{c}{ Exclusion } \\
\hline Community Parks, Farms, Gardens, & Athletic Fields, Barns, Batting Cages, Boathouses, Concessions/Retail/Cafes, Dugouts, \\
Greenhouses, Nursery, Linear Parks, & Environmental Education Centers, Garages/Maintenance/Storage, Golf Courses and Ranges, \\
Parkways, Metropolitan Parks, Mini Parks, & Greenhouses/Nursery, Guard Boxes, Historic Houses, Ice Rinks, Lot/Breezeway/Island, Multi-Use \\
Neighborhood Parks, Regional/Watershed & Area, Multi-Use Building, Museums, Older Adult Centers, Pavilion/Shelter, Pool, Pumping Station, \\
Parks, Square/Plaza Parks, and & Recreation Building, Recreation Center, Recreation Site, Restrooms, Shed, Stables, Stage/Stands, \\
Watershed/Conservation Parks. & Statue/Monument/Sculpture, Weigh Station, Youth and Tot/Play Areas, and Zoo Habitat. \\
\hline
\end{tabular}

Table A3. Association between hypertension and median household income adjusted for age, sex, and race/ethnicity.

\begin{tabular}{|c|c|c|}
\hline & OR $(95 \%$ CI $)$ & $p$-Value \\
\hline \multicolumn{3}{|c|}{ Median Household Income } \\
\hline Q1 & 1.00 (Ref.) & \\
\hline Q2 & $0.78(0.58 ; 1.06)$ & 0.118 \\
\hline Q3 & $0.73(0.53 ; 1.02)$ & 0.064 \\
\hline Q4 & $0.51(0.36 ; 0.72)$ & $<0.001 *$ \\
\hline \multicolumn{3}{|l|}{ Age (years) } \\
\hline $18-34$ & 1.00 (Ref.) & \\
\hline $35-49$ & $3.13(2.04 ; 4.79)$ & $<0.001$ * \\
\hline $50-64$ & $11.26(7.78 ; 16.28)$ & $<0.001 *$ \\
\hline $65+$ & $22.28(15.18 ; 32.71)$ & $<0.001 *$ \\
\hline \multicolumn{3}{|l|}{ Sex } \\
\hline Male & 1.00 (Ref.) & \\
\hline Female & $0.94(0.76 ; 1.16)$ & 0.565 \\
\hline \multicolumn{3}{|l|}{ Race/Ethnicity } \\
\hline NH White ${ }^{1}$ & 1.00 (Ref.) & \\
\hline NH Black ${ }^{1}$ & $2.13(1.64 ; 2.76)$ & $<0.001 *$ \\
\hline Hispanic/Latino & $1.23(0.8 ; 1.89)$ & 0.348 \\
\hline Other & $0.75(0.47 ; 1.21)$ & 0.238 \\
\hline
\end{tabular}

Note: Coefficients are odds ratio (OR), and 95\% confidence interval (CI) are from a weighted logistic regression model using generalized estimating equation (GEE). ${ }^{1} \mathrm{NH}$ indicates non-Hispanic. ${ }^{*} p<0.05$. 
Table A4. Comparison of our study population with the general population of Philadelphia (aged $18+$ years old).

\begin{tabular}{lcc}
\hline & Our Study & Philadelphia * \\
\hline Hypertension (yes) & $38.3 \%$ & $38.2 \%$ \\
\hline Age (years) & & \\
$18-34$ & $30.2 \%$ & $32.4 \%$ \\
$35-49$ & $17.9 \%$ & $29.8 \%$ \\
$50-64$ & $32.7 \%$ & $21.8 \%$ \\
$65+$ & $19.1 \%$ & $16.0 \%$ \\
\hline Sex & & \\
Male & $45.0 \%$ & $46.5 \%$ \\
Female & $55.0 \%$ & $53.5 \%$ \\
\hline Race/Ethnicity & & \\
NH White & $39.9 \%$ & $38.2 \%$ \\
NH Black & $41.4 \%$ & $41.5 \%$ \\
Hispanic/Latino & $12.0 \%$ & $12.6 \%$ \\
Other & $6.8 \%$ & $7.7 \%$
\end{tabular}

${ }^{*}$ Data for Age, Sex, and Race/Ethnicity comes from the 2015 Intercensal Population Estimations for Philadelphia County. Data for Hypertension comes from the Community Health Explorer of the Philadelphia Department of Public Health (https: / healthexplorer.phila.gov/, accessed 4 February 2022). Note that this table shows weighted proportions (Table 1 shows unweighted raw counts).

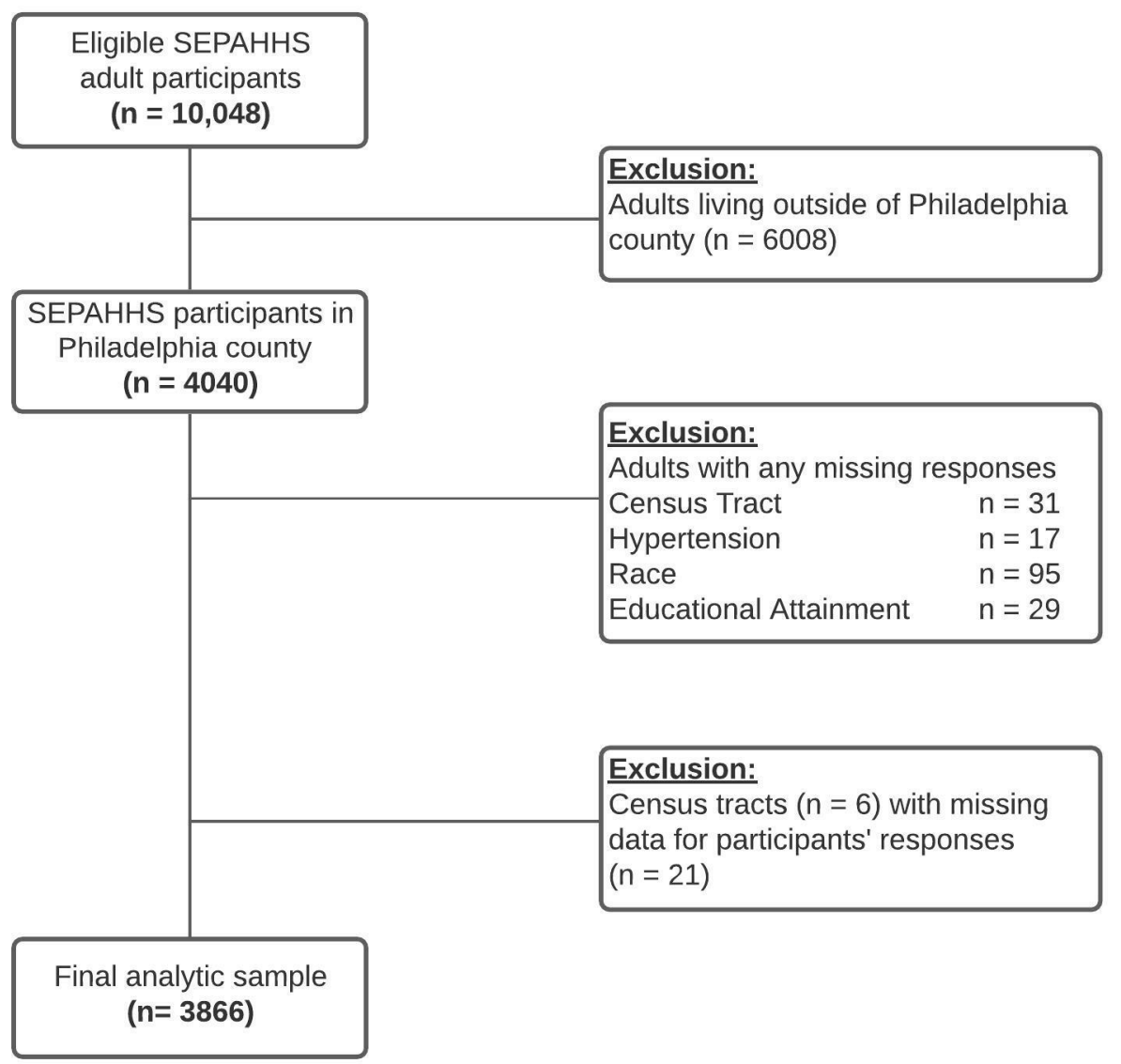

Figure A1. Exclusion criteria of the final analytic sample for the secondary analysis utilizing median household income as the socioeconomic indicator. Note: The 6 census tracts that were missing data from the 2012-2015 American Community Survey are 9803, 9805, 9806, 9807, 9808, and 9809. 

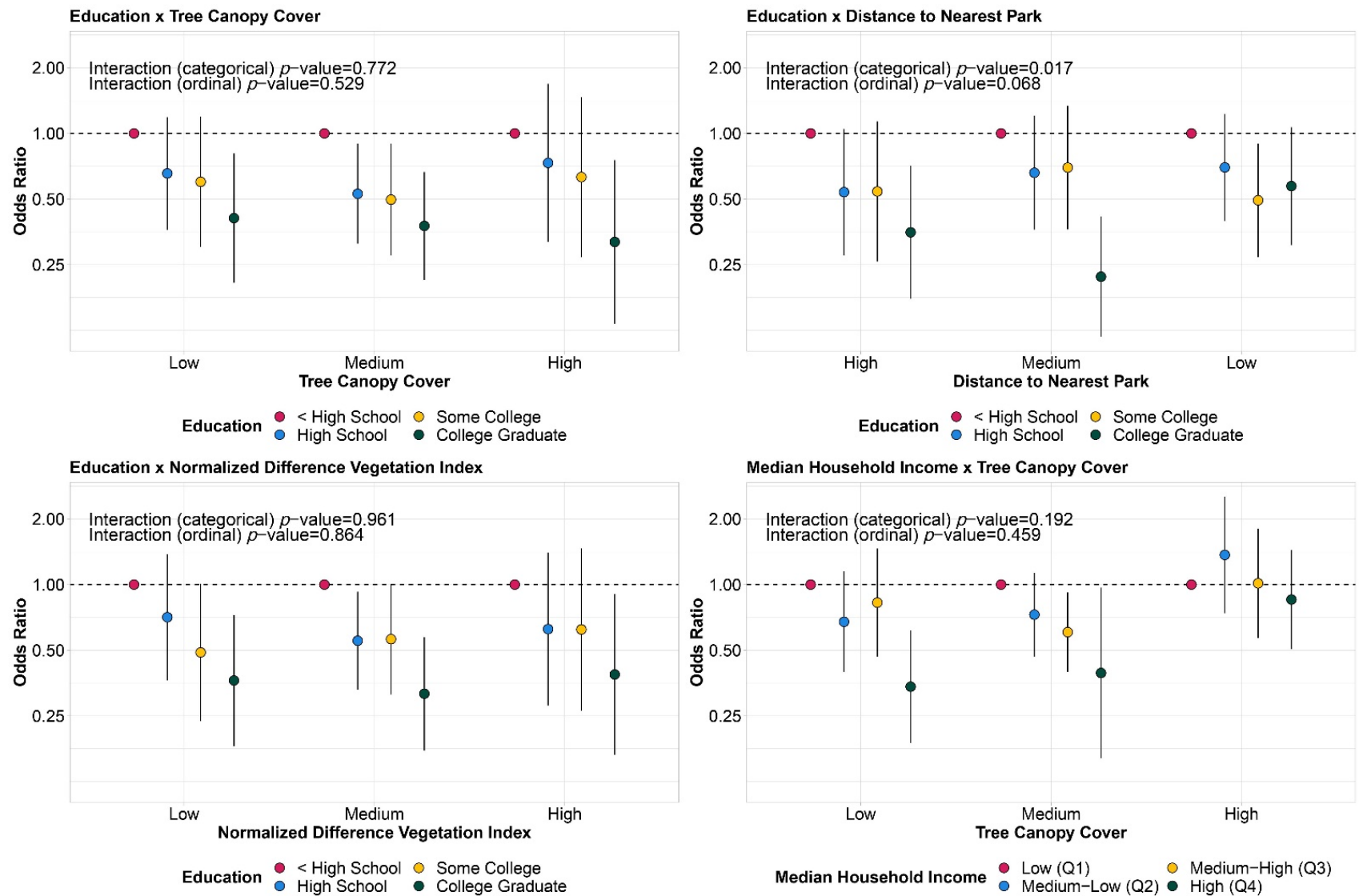

Figure A2. Comparison of main analysis vs. secondary analyses exploring two other green space indicators (mean NDVI and distance to nearest park) and one other socioeconomic indicator (median household income).

\section{References}

1. US EPA. REG 01. "What Is Open Space/Green Space? I Urban Environmental Program in New England". Overviews \& Factsheets. Available online: https:/ / www3.epa.gov/region1/eco/uep/openspace.html (accessed on 12 January 2022).

2. Twohig-Bennett, C.; Jones, A. The health benefits of the great outdoors: A systematic review and meta-analysis of greenspace exposure and health outcomes. Environ. Res. 2018, 166, 628-637. [CrossRef]

3. Maas, J.; Verheij, R.A.; de Vries, S.; Spreeuwenberg, P.; Schellevis, F.G.; Groenewegen, P.P. Morbidity is related to a green living environment. J. Epidemiol. Community Health 2009, 63, 967-973. [CrossRef]

4. Wolch, J.R.; Byrne, J.; Newell, J.P. Urban green space, public health, and environmental justice: The challenge of making cities 'just green enough'. Landsc. Urban Plan. 2014, 125, 234-244. [CrossRef]

5. Department of Economic and Social Affairs; United Nations. World Urbanization Prospects: The 2018 Revision (ST/ESA/SER.A/420). United Nations, New York. 2019. Available online: https:/ / population.un.org/wup/Publications/Files/WUP2018-Report.pdf (accessed on 12 January 2022).

6. Ali, M.U.; Liu, G.; Yousaf, B.; Ullah, H.; Abbas, Q.; Munir, M.A.M. A systematic review on global pollution status of particulate matter-associated potential toxic elements and health perspectives in urban environment. Environ. Geochem. Heal. 2018, 41, 1131-1162. [CrossRef]

7. Frumkin, H. Urban sprawl and public health. Public Health Rep. 2002, 117, 201-217. [CrossRef]

8. US EPA. Green Streets and Community Open Space. 11 January 2018. Available online: https://www.epa.gov/G3/green-streetsand-community-open-space (accessed on 12 January 2022).

9. Kondo, M.C.; Fluehr, J.M.; McKeon, T.P.; Branas, C.C. Urban Green Space and Its Impact on Human Health. Int. J. Environ. Res. Public Heal. 2018, 15, 445. [CrossRef]

10. Richardson, E.A.; Mitchell, R.; Hartig, T.; de Vries, S.; Astell-Burt, T.; Frumkin, H. Green cities and health: A question of scale? J. Epidemiol. Community Health 2012, 66, 160-165. [CrossRef]

11. Taylor, L.; Hochuli, D.F. Defining greenspace: Multiple uses across multiple disciplines. Landsc. Urban Plan. 2017, 158, 25-38. [CrossRef]

12. Astell-Burt, T.; Feng, X. Urban green space, tree canopy and prevention of cardiometabolic diseases: A multilevel longitudinal study of 46786 Australians. Int. J. Epidemiol. 2020, 49, 926-933. [CrossRef] 
13. Wheeler, B.W.; Lovell, R.; Higgins, S.L.; White, M.P.; Alcock, I.; Osborne, N.J.; Husk, K.; Sabel, C.E.; Depledge, M.H. Beyond greenspace: An ecological study of population general health and indicators of natural environment type and quality. Int. J. Health Geogr. 2015, 14, 17. [CrossRef]

14. Aram, F.; Garcia, E.H.; Solgi, E.; Mansournia, S. Urban green space cooling effect in cities. Heliyon 2019, 5, e01339. [CrossRef]

15. Nowak, D.J.; Crane, D.E.; Stevens, J.C. Air pollution removal by urban trees and shrubs in the United States. Urban For. Urban Green. 2006, 4, 115-123. [CrossRef]

16. Liu, W.; Chen, W.; Peng, C. Assessing the effectiveness of green infrastructures on urban flooding reduction: A community scale study. Ecol. Model. 2014, 291, 6-14. [CrossRef]

17. Brown, S.C.; Perrino, T.; Lombard, J.; Wang, K.; Toro, M.; Rundek, T.; Gutierrez, C.M.; Dong, C.; Plater-Zyberk, E.; Nardi, M.I.; et al. Health Disparities in the Relationship of Neighborhood Greenness to Mental Health Outcomes in 249,405 U.S. Medicare Beneficiaries. Int. J. Environ. Res. Public Health 2018, 15, 430. [CrossRef] [PubMed]

18. Lachowycz, K.; Jones, A.P. Greenspace and obesity: A systematic review of the evidence. Obes. Rev. 2011, 12, e183-e189. [CrossRef]

19. Akpinar, A. How is quality of urban green spaces associated with physical activity and health? Urban For. Urban Green. 2016, 16, 76-83. [CrossRef]

20. Richardson, E.; Pearce, J.; Mitchell, R.; Kingham, S. Role of physical activity in the relationship between urban green space and health. Public Health 2013, 127, 318-324. [CrossRef]

21. Jennings, V.; Bamkole, O. The Relationship between Social Cohesion and Urban Green Space: An Avenue for Health Promotion. Int. J. Environ. Res. Public Health 2019, 16, 452. [CrossRef]

22. Brunner, E. Socioeconomic determinants of health: Stress and the biology of inequality. BMJ 1997, 314, 1472. [CrossRef]

23. Lee, J.; Tsunetsugu, Y.; Takayama, N.; Park, B.-J.; Li, Q.; Song, C.; Komatsu, M.; Ikei, H.; Tyrväinen, L.; Kagawa, T.; et al. Influence of Forest Therapy on Cardiovascular Relaxation in Young Adults. Evid. Based Complementary Altern. Med. 2014, $2014,1-7$. [CrossRef]

24. Mobley, L.R.; Root, E.; Finkelstein, E.A.; Khavjou, O.; Farris, R.P.; Will, J.C. Environment, Obesity, and Cardiovascular Disease Risk in Low-Income Women. Am. J. Prev. Med. 2006, 30, 327-332.e1. [CrossRef] [PubMed]

25. Dzhambov, A.M.; Markevych, I.; Lercher, P. Greenspace seems protective of both high and low blood pressure among residents of an Alpine valley. Environ. Int. 2018, 121, 443-452. [CrossRef] [PubMed]

26. Browning, M.H.; Rigolon, A.; McAnirlin, O.; McAnirlin, O. Where greenspace matters most: A systematic review of urbanicity, greenspace, and physical health. Landsc. Urban Plan. 2021, 217, 104233. [CrossRef]

27. Zhang, L.; Tan, P.Y. Associations between Urban Green Spaces and Health are Dependent on the Analytical Scale and How Urban Green Spaces are Measured. Int. J. Environ. Res. Public Health 2019, 16, 578. [CrossRef]

28. Knobel, P.; Kondo, M.; Maneja, R.; Zhao, Y.; Dadvand, P.; Schinasi, L.H. Associations of objective and perceived greenness measures with cardiovascular risk factors in Philadelphia, PA: A spatial analysis. Environ. Res. 2021, 197, 110990. [CrossRef]

29. Mitchell, R.; Popham, F. Effect of exposure to natural environment on health inequalities: An observational population study. Lancet 2008, 372, 1655-1660. [CrossRef]

30. Tamosiunas, A.; Grazuleviciene, R.; Luksiene, D.; Dedele, A.; Reklaitiene, R.; Baceviciene, M.; Vencloviene, J.; Bernotiene, G.; Radisauskas, R.; Malinauskiene, V.; et al. Accessibility and use of urban green spaces, and cardiovascular health: Findings from a Kaunas cohort study. Environ. Health 2014, 13, 20. [CrossRef]

31. Wilker, E.H.; Wu, C.-D.; McNeely, E.; Mostofsky, E.; Spengler, J.; Wellenius, G.A.; Mittleman, M.A. Green space and mortality following ischemic stroke. Environ. Res. 2014, 133, 42-48. [CrossRef]

32. Liburd, L.C.; Hall, J.E.; Mpofu, J.J.; Williams, S.M.; Bouye, K.; Penman-Aguilar, A. Addressing Health Equity in Public Health Practice: Frameworks, Promising Strategies, and Measurement Considerations. Annu. Rev. Public Health 2020, 41, 417-432. [CrossRef]

33. Krieger, N.; Williams, D.R.; Moss, N.E. Measuring Social Class in US Public Health Research: Concepts, Methodologies, and Guidelines. Annu. Rev. Public Health 1997, 18, 341-378. [CrossRef]

34. Loucks, E.B.; Abrahamowicz, M.; Xiao, Y.; Lynch, J.W. Associations of education with 30 year life course blood pressure trajectories: Framingham Offspring Study. BMC Public Health 2011, 11, 139. [CrossRef] [PubMed]

35. Camacho, P.A.; Gomez-Arbelaez, D.; Molina, D.I.; Sanchez, G.; Arcos, E.; Narvaez, C.; García, H.; Pérez, M.; Hernandez, E.A.; Duran, M.; et al. Social disparities explain differences in hypertension prevalence, detection and control in Colombia. J. Hypertens. 2016, 34, 2344-2352. [CrossRef] [PubMed]

36. Rosengren, A.; Subramanian, S.V.; Islam, S.; Chow, C.K.; Avezum, A.; Kazmi, K.; Sliwa, K.; Zubaid, M.; Rangarajan, S.; Yusuf, S.; et al. Education and risk for acute myocardial infarction in 52 high, middle and low-income countries: INTERHEART case-control study. Heart 2009, 95, 2014-2022. [CrossRef] [PubMed]

37. Rosengren, A.; Smyth, A.; Rangarajan, S.; Ramasundarahettige, C.; Bangdiwala, S.I.; Alhabib, K.F.; Avezum, A.; Boström, K.B.; Chifamba, J.; Gulec, S.; et al. Socioeconomic status and risk of cardiovascular disease in 20 low-income, middle-income, and high-income countries: The Prospective Urban Rural Epidemiologic (PURE) study. Lancet Glob. Health 2019, 7, e748-e760. [CrossRef]

38. Gullón, P.; Díez, J.; Cainzos-Achirica, M.; Franco, M.; Bilal, U. Social inequities in cardiovascular risk factors in women and men by autonomous regions in Spain. Gac. Sanit. 2021, 35, 326-332. [CrossRef] 
39. Bromfield, S.; Muntner, P. High Blood Pressure: The Leading Global Burden of Disease Risk Factor and the Need for Worldwide Prevention Programs. Curr. Hypertens. Rep. 2013, 15, 134-136. [CrossRef]

40. Leng, B.; Jin, Y.; Li, G.; Chen, L.; Jin, N. Socioeconomic status and hypertension. J. Hypertens. 2015, 33, 221-229. [CrossRef]

41. GBD 2019 Risk Factors Collaborators. Global burden of 87 risk factors in 204 countries and territories, 1990-2019: A systematic analysis for the Global Burden of Disease Study 2019. Lancet 2019, 396, 1223-1249. [CrossRef]

42. Bureau, US Census. Educational Attainment. Available online: https://www.census.gov/topics/education/educationalattainment.html (accessed on 2 February 2022).

43. Bureau, US Census. Income. Available online: https://www.census.gov/topics/income-poverty/income.html (accessed on 6 February 2022).

44. Chum, A.; O'Campo, P. Cross-sectional associations between residential environmental exposures and cardiovascular diseases. BMC Public Health 2015, 15, 438. [CrossRef]

45. Grazuleviciene, R.; Dedele, A.; Danileviciute, A.; Vencloviene, J.; Grazulevicius, T.; Andrusaityte, S.; Uzdanaviciute, I.; Nieuwenhuijsen, M.J. The Influence of Proximity to City Parks on Blood Pressure in Early Pregnancy. Int. J. Environ. Res. Public Health 2014, 11, 2958-2972. [CrossRef]

46. Grazuleviciene, R.; Andrusaityte, S.; Gražulevičius, T.; Dèdelè, A. Neighborhood Social and Built Environment and Disparities in the Risk of Hypertension: A Cross-Sectional Study. Int. J. Environ. Res. Public Health 2020, 17, 7696. [CrossRef]

47. Brown, S.C.; Lombard, J.; Wang, K.; Byrne, M.M.; Toro, M.; Plater-Zyberk, E.; Feaster, D.J.; Kardys, J.; Nardi, M.I.; PerezGomez, G.; et al. Neighborhood Greenness and Chronic Health Conditions in Medicare Beneficiaries. Am. J. Prev. Med. 2016, 51, 78-89. [CrossRef] [PubMed]

48. Citywide Cluster Randomized Trial to Restore Blighted Vacant Land and Its Effects on Violence, Crime, and Fear I PNAS. Available online: https:/ / www.pnas.org/content/115/12/2946.short (accessed on 13 January 2022).

49. Frontiers I Three Histories of Greening and Whiteness in American Cities IEcology and Evolution. Available online: https:/ / www.frontiersin.org/articles/10.3389/fevo.2021.621783/full?\&utm_source=Email_to_authors_\&utm_medium= Email\&utm_content=T1_11.5e1_author\&utm_campaign=Email_publication\&field=\&journalName=Frontiers_in_Ecology_ and_Evolution\&id=621783 (accessed on 13 January 2022).

50. PHILA2035. THE PLAN. Available online: https://www.phila2035.org/plan (accessed on 20 January 2022).

51. Bureau, US Census. Glossary. Available online: https://www.census.gov/programs-surveys/geography/about/glossary.html (accessed on 16 November 2021).

52. 2014-2015 Southeastern Pennsylvania (SEPA) Household Health Survey. Available online: https://research.phmc.org/52-projectspotlight/248-southeastern-pennsylvania-household-health-survey (accessed on 16 November 2021).

53. Bilal, U.; Tabb, L.P.; Barber, S.S.; Roux, A.V.D. Spatial Inequities in COVID-19 Testing, Positivity, Confirmed Cases, and Mortality in 3 U.S. Cities. Ann. Intern. Med. 2021, 174, 936-944. [CrossRef] [PubMed]

54. Brown, E.J.; Polsky, D.; Barbu, C.M.; Seymour, J.; Grande, D. Racial Disparities In Geographic Access To Primary Care In Philadelphia. Health Aff. 2016, 35, 1374-1381. [CrossRef] [PubMed]

55. Quick, H.; Terloyeva, D.; Wu, Y.; Moore, K.; Roux, A.V.D. Trends in Tract-Level Prevalence of Obesity in Philadelphia by Race-Ethnicity, Space, and Time. Epidemiology 2020, 31, 15-21. [CrossRef] [PubMed]

56. Mudd, A.E.; Michael, Y.L.; Melly, S.; Moore, K.; Diez-Roux, A.; Forrest, C.B. Spatial accessibility to pediatric primary care in Philadelphia: An area-level cross sectional analysis. Int. J. Equity Health 2019, 18, 76. [CrossRef] [PubMed]

57. U.S. Census Bureau. 2012-2016 American Community Survey 5-Year Estimates, American FactFinder. Available online: https:// www.census.gov/programs-surveys/acs/technical-documentation/table-and-geography-changes/2016/5-year.html (accessed on 13 January 2022).

58. Chesapeake Conservancy. Land Cover Data Project 2013/2014. Available online: https://chesapeakeconservancy.org/ conservation-innovation-center-2/high-resolution-data/land-cover-data-project/ (accessed on 13 December 2020).

59. Earth Explorer; 2022; FS; 083-00; Geological Survey (U.S.). Available online: https://earthexplorer.usgs.gov/ (accessed on 16 November 2021).

60. Parks and Recreation Assets. Open Data Philly. July 2019. Available online: https://www.opendataphilly.org/dataset/parksand-recreation-assets (accessed on 5 January 2021).

61. Esri Inc. ArcGIS Pro, version 2.9.1; Software; Esri Inc.: Redlands, CA, USA, 2016.

62. Williams, D.R. Understanding Associations between Race, Socioeconomic Status and Health: Patterns and Prospects. Health Psychol. 2016, 35, 407-411. [CrossRef] [PubMed]

63. Wen, M.; Zhang, X.; Harris, C.D.; Holt, J.B.; Croft, J.B. Spatial Disparities in the Distribution of Parks and Green Spaces in the USA. Ann. Behav. Med. 2013, 45, 18-27. [CrossRef]

64. R Core Team. R: A Language and Environment for Statistical Computing; R Foundation for Statistical Computing: Vienna, Austria, 2020. Available online: https:/ / www.R-project.org/ (accessed on 5 January 2021).

65. Martin, L.M.; Leff, M.; Calonge, N.; Garrett, C.; Nelson, D.E. Validation of self-reported chronic conditions and health services in a managed care population. Am. J. Prev. Med. 2000, 18, 215-218. [CrossRef]

66. Kondo, M.C.; Clougherty, J.E.; Hohl, B.C.; Branas, C.C. Gender Differences in Impacts of Place-Based Neighborhood Greening Interventions on Fear of Violence Based on a Cluster-Randomized Controlled Trial. J. Hered. 2021, 98, 812-821. [CrossRef] 